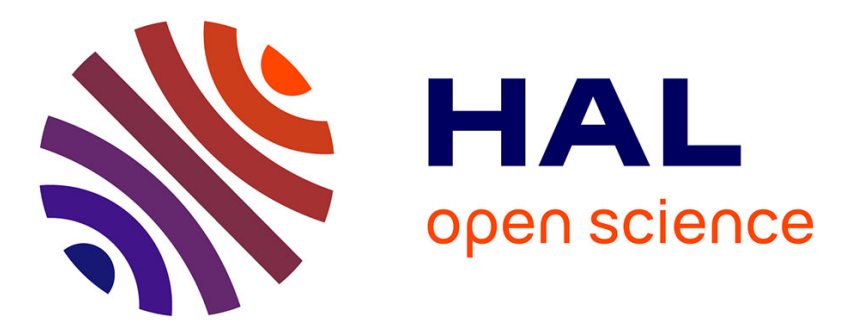

\title{
A low cycle fatigue model for low carbon manganese steel including the effect of dynamic strain aging
}

Zhi Yong Huang, Danièle Wagner, Qing Yuan Wang, Muhammad Kashif Khan, Jean Louis Chaboche

\section{- To cite this version:}

Zhi Yong Huang, Danièle Wagner, Qing Yuan Wang, Muhammad Kashif Khan, Jean Louis Chaboche. A low cycle fatigue model for low carbon manganese steel including the effect of dynamic strain aging. Materials Science and Engineering, 2015, 654 (pages 77-84), 10.1016/j.msea.2015.12.022 . hal-01426388

\section{HAL Id: hal-01426388 \\ https://hal.science/hal-01426388}

Submitted on 18 Jan 2018

HAL is a multi-disciplinary open access archive for the deposit and dissemination of scientific research documents, whether they are published or not. The documents may come from teaching and research institutions in France or abroad, or from public or private research centers.
L'archive ouverte pluridisciplinaire HAL, est destinée au dépôt et à la diffusion de documents scientifiques de niveau recherche, publiés ou non, émanant des établissements d'enseignement et de recherche français ou étrangers, des laboratoires publics ou privés. 


\title{
A low cycle fatigue model for low carbon manganese steel including the effect of dynamic strain aging
}

\author{
Zhi Yong Huang ${ }^{\mathrm{a}, *}$, Danièle Wagner ${ }^{\mathrm{b}}$, Qing Yuan Wang ${ }^{\mathrm{a}}$, Muhammad Kashif Khan ${ }^{\mathrm{a}}$, \\ Jean-Louis Chaboche ${ }^{\mathrm{c}}$ \\ a Sichuan University, School of Aeronautics and Astronautics, No.29 Jiuyanqiao Wangjiang Road, Chengdu 610064, China \\ ${ }^{\mathrm{b}}$ Université Paris Ouest Nanterre La Défense, France \\ c ONERA, DMSM, 29 avenue de la Division Lecerc, F-92320, Chatillon, France
}

A B S T R A C T

Keywords:

Carbon manganese steel

Cyclic hardening

Dynamic strain aging

Low cycle fatigue
Carbon-manganese steel A48 (French standards) is used in steam generator pipes of the nuclear power plant where it is subjected to the cyclic thermal load. The Dynamic Strain Aging (DSA) influences the mechanical behavior of the steel in low cycle fatigue (LCF) at favorable temperature and strain rate. The peak stress of A48 steel experiences hardening-softening-hardening $(\mathrm{HSH})$ evolution at $200{ }^{\circ} \mathrm{C}$ and $0.4 \% \mathrm{~s}^{-1}$ strain rate in fatigue loading. In this study, isotropic and kinematic hardening rules with DSA effect have been modified. The HSH evolution of cyclic stress associated with cumulative plastic deformation has also been estimated.

\section{Introduction}

Low Cycle Fatigue (LCF) loading produce damage in the service life of steam generator feed water lines of the Pressurized Water Reactor (PWR) [1,2]. The insufficient killed steel A48 used in these reactors is sensitive to the loading with different strain rates. Due to this, the metallurgical instabilities like Lüders bands, Portevin-le Chatelier bands [3-5] and DSA under tensile and fatigue loading are common in the alloy. DSA appears due to the interaction of strong solute atoms pinning and dislocations. The solute atoms are capable of diffusing over the short distance and arrest mobile dislocations at specific strain rate and temperature range. The strain rate sensitivity coefficient becomes negative due to DSA which helps in development of localized deformation bands (Portevin - Le Chatelier) in the monotonic tensile loading [5]. In low cycle fatigue, double cyclic hardening is observed in the peak tensile stress evolution [6].

Though multi-scale approaches have made great progress in the past 20 years, the existing macroscopical model of the constitutive framework is still widely used in the structure simulation and needs further improvement at continuum scale. The use of the yield surface in macroscopic cyclic plasticity theories ensures the accurate description of the Bauschinger effect. The Armstrong and

\footnotetext{
* Corresponding author.

E-mail address: huangzy@scu.edu.cn (Z.Y. Huang).
}

Frederick (A-F) [7] model, improved by Chaboche [8], Cailletaud [9], Macdowell [10], Ohno [11], Kang [12] and Khan [13] is suitable for the description of cyclic kinematic hardening. The splitting of the back stress into several parts was found to be successful for kinematic hardening in the LCF. The memory surface was introduced to well estimate the strain amplitude and loading sequences effects for the cyclic plasticity [14-15]. Recently, the cyclic viscoplastic modeling of the combustion chamber of aircraft engine material was investigated with DSA effect at elevated temperature [16].

This article focuses on the DSA effect on the LCF kinematic and isotropic hardening for the low carbon manganese steel. An improved constitutive model with DSA effects is proposed based on the thermodynamic framework and dislocation theory. The strain rate dependent rules of kinematic and isotropic hardening consider the interaction of the interstitial atoms with the gliding dislocations for stress - strain hysteretic response. The experimental results have been validated by implicit numerical integration method.

\section{Material and testing}

A48 steel is a kind of low carbon manganese steel (AFNOR NFA 36205 French Standard) which is used in the feed water line of French nuclear power plants [17]. A $40 \mathrm{~mm}$ thick plate undergoes a prior normalization and austenitising heat treatment at $870{ }^{\circ} \mathrm{C}$ 


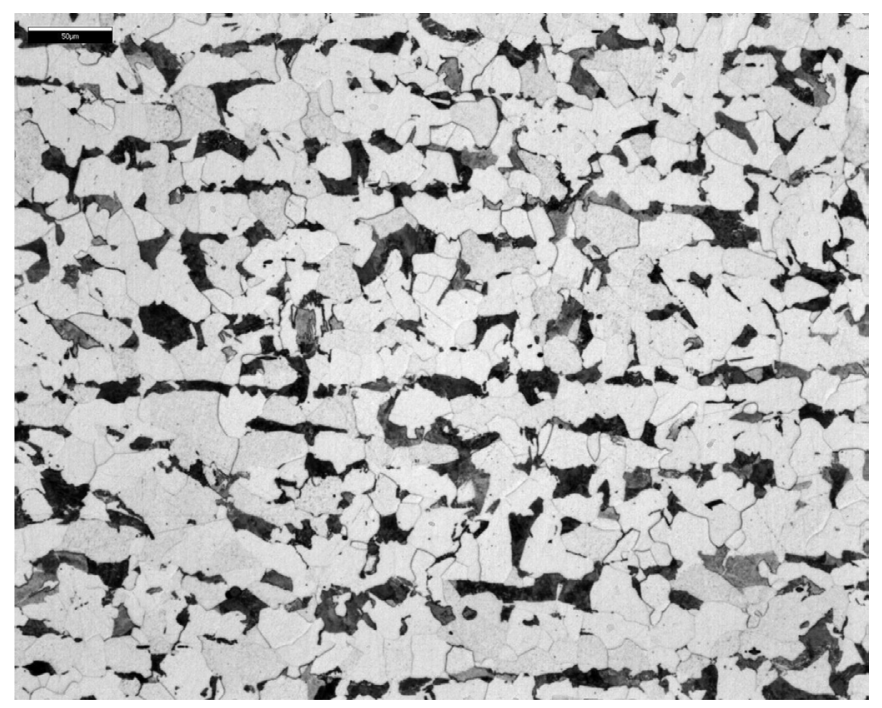

Fig. 1. Microstructure of A48 steel.

followed by air cooling. This forms a banded ferrite and pearlite grain distribution in the microstructure (Fig.1). Table 1 shows the chemical composition in weight percentage for the steel.

Low cycle fatigue specimen was designed as shown in Fig. 2. Low cycle fatigue tests were conducted under strain control mode in the hydraulic fatigue test machine (Instron 8501) at 0.4, 0.6 and $0.8 \%$ strain amplitude at $200{ }^{\circ} \mathrm{C}$ and $0.4 \% \mathrm{~s}^{-1}$ strain rate.

The peak tensile stress curves are shown in Fig.3 at the strain amplitudes of $0.4,0.6$ and $0.8 \%$ at $200{ }^{\circ} \mathrm{C}$. The cyclic stress response was dependent on the testing temperature and strain rate as shown in Fig. 4. It can be seen that there was an initial cyclic hardening after several loading cycles. This followed by a weak softening resulting in a secondary hardening at $200{ }^{\circ} \mathrm{C}$ in Fig.3.

Fig. 5 shows the LCF hysteresis loops for A48 at a strain rate of $0.4 \% \mathrm{~s}^{-1}$ and $0.8 \%$ strain amplitude and $200{ }^{\circ} \mathrm{C}$. The cyclic yield stress was obtained by the LCF test data (Fig. 5). It was found that the increase in cumulative plastic deformation change the stressstrain hysteretic response. The tangent slopes of the stress-strain hysteresis loops at the strain amplitude have been measured from the experimental data and shown in Figs. 6 and 7. The slopes grow significantly with increase in the number of cycles. However, the cyclic yield stress remained stable and showed the similar HSH behavior as shown in Fig. 8. This will be further discussed later in the article.

\section{Modeling}

\subsection{Thermodynamic framework}

In LCF, the plastic deformation forms hysteresis loop at the macroscopic scale. The thermodynamic potential $(\psi)$ and the dissipation potential $\left(\phi^{*}\right)$ functions are given by:

$\psi=\psi\left(\varepsilon^{e}, T, \alpha_{i}\right)$

$\phi^{*}=\phi^{*}\left(\sigma, A_{j}, \varepsilon^{e}, T, a_{j}\right)$

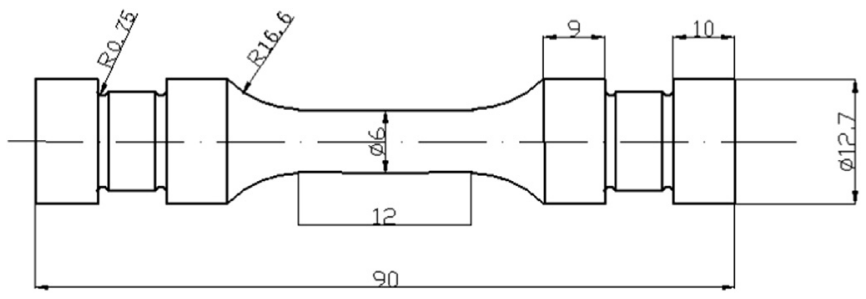

Fig. 2. Schematic illustration of low cycle fatigue specimen.

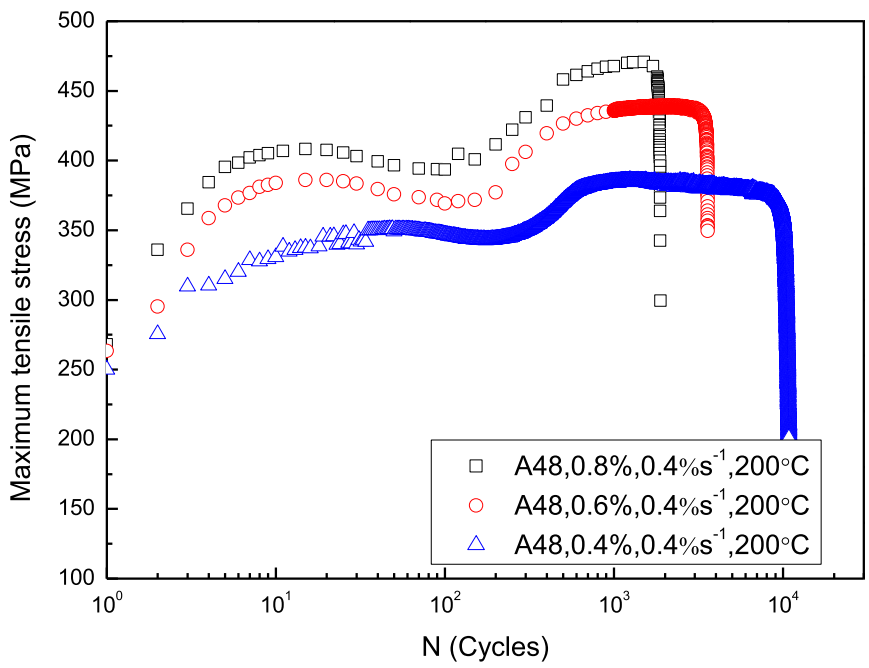

Fig. 3. Peak stress evolutions of $A 48$ at $0.8 \%, 0.6 \%$ and $0.4 \%$ strain amplitudes in LCF with $0.4 \% \mathrm{~s}^{-1}$ strain rate at $200{ }^{\circ} \mathrm{C}$.

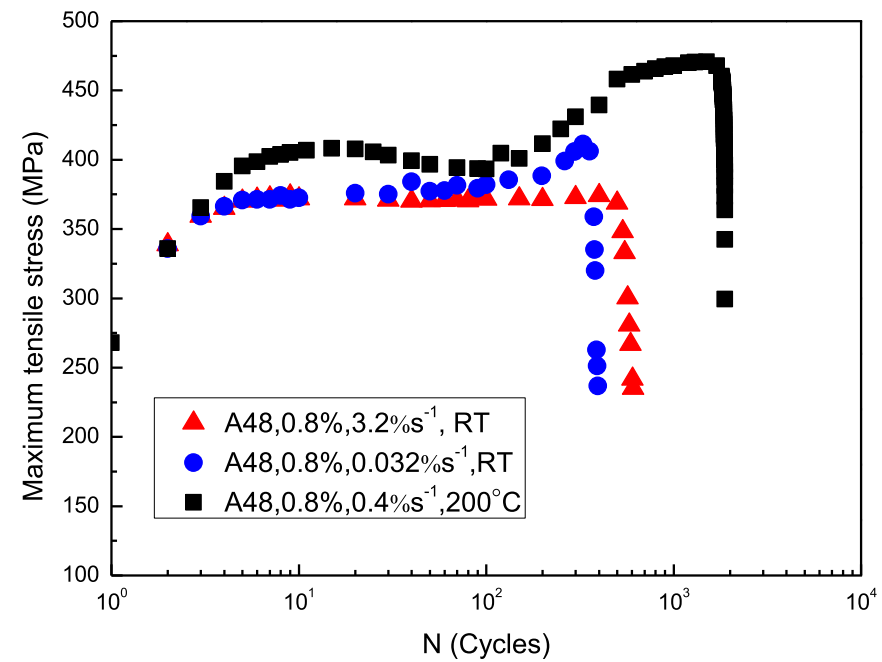

Fig. 4. A48 stress amplitude evolutions for $\varepsilon_{a}=0.8 \%$ at room temperature at different strain rates.

$\psi, \phi^{*}$ are the functions which are assumed as follows [8]:

$\rho \psi=\frac{1}{2} \mathrm{D}_{\mathrm{e}}: \varepsilon^{\mathbf{e}}: \varepsilon^{\mathbf{e}}+\frac{1}{3} h \mathbf{a}: \mathbf{a}+W(r, T)$

Table 1

Chemical composition (wt\%).

\begin{tabular}{|c|c|c|c|c|c|c|c|c|c|c|c|c|}
\hline$C$ & $S$ & $\mathrm{P}$ & $\mathrm{Si}$ & Mn & $\mathrm{Ni}$ & $\mathrm{Cr}$ & Mo & $\mathrm{Cu}$ & Sn & $\mathrm{Al}$ & $\mathrm{N}$ & 0 \\
\hline 0.140 & 0.0057 & 0.016 & 0.225 & 0.989 & 0.024 & 0.021 & 0.002 & 0.027 & 0.003 & 0.045 & 0.0082 & 0.0006 \\
\hline
\end{tabular}




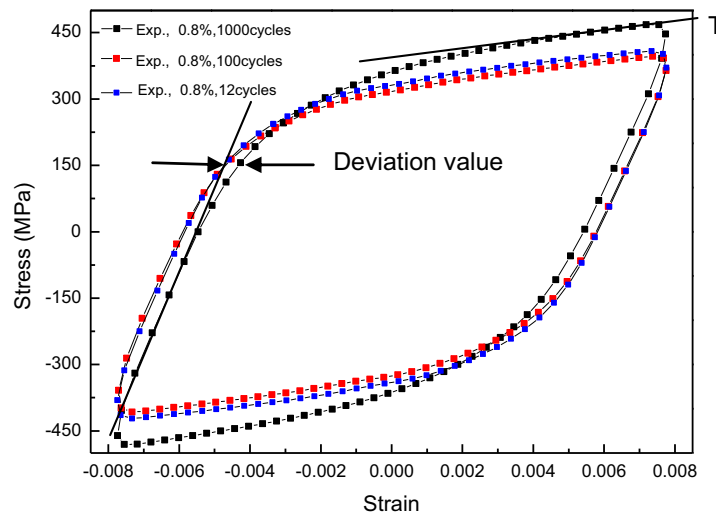

Fig. 5. Hysteresis loops for $\mathrm{A} 48$ at $200{ }^{\circ} \mathrm{C}, 0.8 \%$ strain amplitude.

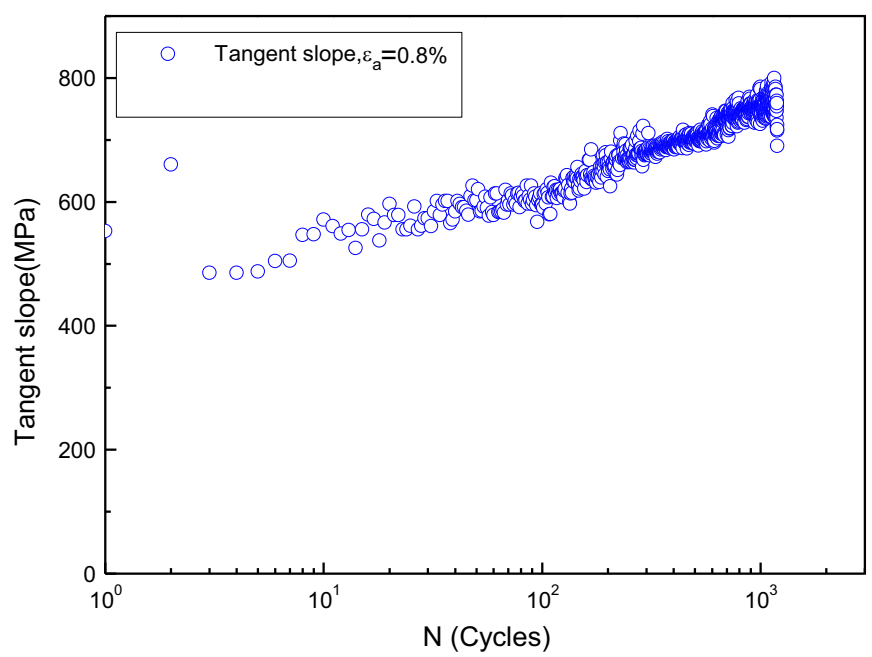

Fig. 6. Tangent slopes measured from $0.8 \%$ strain amplitude test results for A48 at $200{ }^{\circ} \mathrm{C}$ and $0.4 \% \mathrm{~s}^{-1}$.

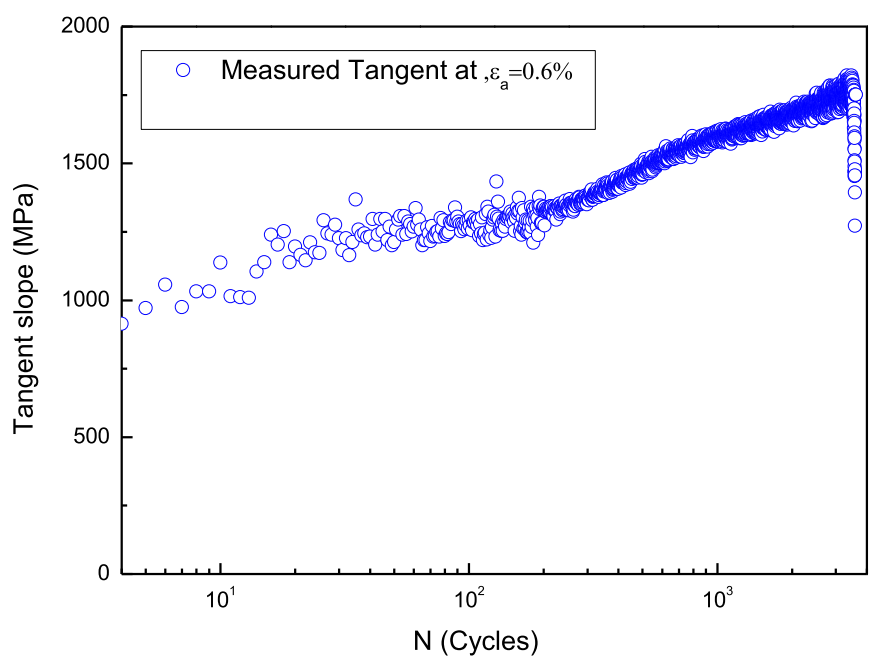

Fig. 7. Tangent slopes at the end of loops measured from $0.6 \%$ strain amplitude test results for $\mathrm{A} 48$ at $200{ }^{\circ} \mathrm{C}$ and $0.4 \% \mathrm{~s}^{-1}$.

$\phi^{*}=g=g\left(J(\boldsymbol{\sigma}-\boldsymbol{\alpha})-R-k+\frac{3 \zeta}{4 h} \boldsymbol{\alpha}: \boldsymbol{\alpha}\right)=g\left(f+\frac{3 \zeta}{4 h} \boldsymbol{\alpha}: \boldsymbol{\alpha}\right)$

where $T$ is the temperature; $\varepsilon^{e}$ is the elastic strain tensor; $a_{j}$ is the family of internal variables to describe the current state of the material.

The mechanical variables are deduced from the functions based

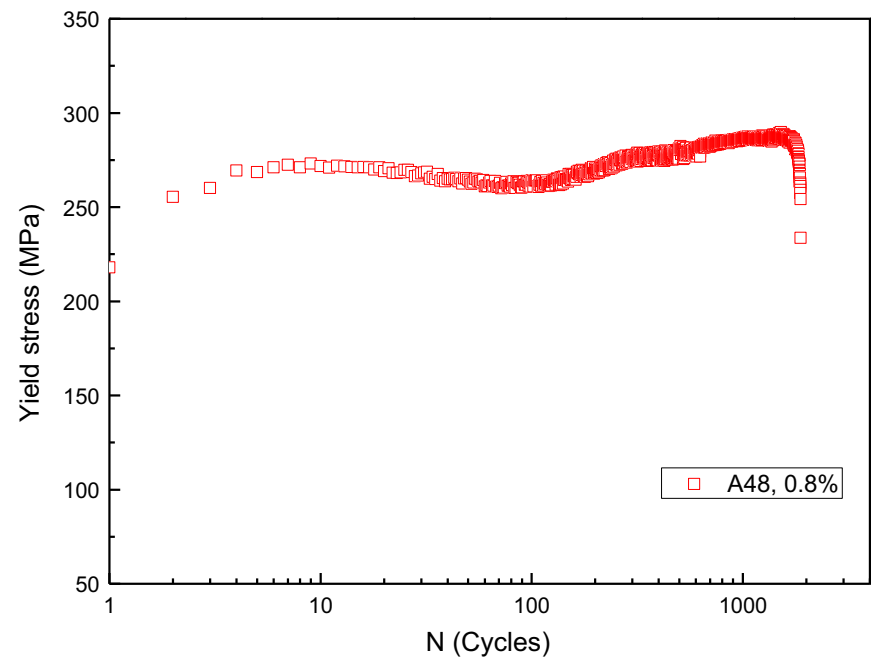

Fig. 8. Cyclic yield stress evolution obtained from test results for A48 steel at $200{ }^{\circ} \mathrm{C}$ and $0.4 \% \mathrm{~s}^{-1}, 0.8 \%$ amplitude.

on the second law of thermodynamics which leads to:

$\boldsymbol{\sigma}=\rho \frac{\partial \psi}{\partial \mathbf{\varepsilon}^{\mathbf{e}}}, \cdot S=-\frac{\partial \psi}{\partial T}, \mathbf{A}_{\mathbf{j}}=\rho \frac{\partial \psi}{\partial \mathbf{a}_{\mathbf{j}}}$

$\dot{\varepsilon}^{\mathbf{p}}=\frac{\partial \phi^{*}}{\partial \boldsymbol{\sigma}}, \dot{\mathbf{a}}_{\mathbf{j}}=-\frac{\partial \phi^{*}}{\partial \mathbf{A}_{\mathbf{j}}}$

where $\mathbf{a}$ is the internal "strain variable" associated with the center $\boldsymbol{\alpha}$ of the elastic domain, $r$ is the isotropic variable, related with $R$. $\mathbf{D}_{\mathbf{e}}$ is the elastic matrix.

\subsection{Isotropic hardening with DSA effect}

The isotropic hardening of A48 steel can be divided into primary hardening, softening and secondary hardening. The dislocation density in the ferrite grains increases in the initial phase of cyclic hardening as shown in Transmission Electron Micrograph (TEM) analysis [18]. For the two phases (ferrite and pearlite) steel [18], the deformation seems to appear mainly in the ferrite grains. Hence, the pearlite grains can be considered as of high strength in the ferrite matrix. The interstitial atoms in the solid solution can accumulate around the dislocations and develop into the so called Cottrell clouds [5]. Due to DSA, the interaction of the interstitial atoms with the gliding dislocations changes the arrangement and a different wall structure develops and the dislocations show veins and tangles.

In Fig. 4, the first isotropic hardening at $200{ }^{\circ} \mathrm{C}$ with $0.4 \% \mathrm{~s}^{-1}$ strain rate is higher than that at room temperature with $3.2 \% \mathrm{~s}^{-1}$ and $0.032 \% \mathrm{~s}^{-1}$ might be induced by the dislocations multiplication and DSA effect. With increase in the thermal activation, the mobility of dislocations would increase. However, the dislocations mobility decrease because of the interaction with the solute atoms at a certain temperature range where diffusion of the solute atoms is sufficiently high. Some dislocations at nucleation sites such as dislocation forest and the grain boundary can be arrested and form the obstacles of the mobile dislocation during LCF strain loading.

The following cyclic softening behavior observed at $200{ }^{\circ} \mathrm{C}$ in Fig. 3 shows that the plastic deformation occur easily at high temperature under the relative lower flow stress due to the reorganization process of dislocations at a certain strain rate. The Transmission Electron Microscopy (TEM) observation from an earlier study [19] showed that the dislocation density and the 
micro structure formation (dense dislocation veins/walls) process due to the insufficient mobile dislocation locked by the interstitial atoms at cell wall leading to the cyclic softening.

The most significant consequence of the higher dislocation density and the veins/walls structure formation is the second cyclic hardening which is more pronounced than the first one. The secondary hardening is observed even at room temperature (RT) and low strain rate $\left(0.032 \% \mathrm{~s}^{-1}\right)$, as shown in Fig. 4 . This may be attributed to DSA effect in which a stronger interaction between the higher dislocation with dense wall/vein structure and solute atoms in LCF takes place. The dislocation motion glides and shows pile up against the wall. The dislocations are arrested and move to the opposite wall with change in the stress direction. The walls serve as obstacles in arresting the dislocations during the waiting time $t_{w}$. In an earlier study as well [12], the secondary hardening in low carbon steel due to the DSA effect was observed.

Initially, the onset cycle for each period need to be determined. The primary hardening starts from the beginning of the test through the observation of the curves in Fig. 3.

A total time of the dislocations movement between the walls in the ferrite grains is considered as [6]:

$t_{t}=t_{w}+t_{f}$

Where, $t_{w}$ is the waiting time at the wall and $t_{f}$ is the flight time between the walls. The time required for dislocations to lock at the walls is termed as the waiting time $\left(t_{w}\right)$ by the diffusion atoms.

For the secondary isotropic hardening, the dislocation accumulation at a certain critical cycle $\left(N_{C}\right)$, the aging time $t_{a}$ becomes equal to $t_{w}$ and the dislocations can be arrested largely at the walls [19]. The $t_{a}$ is the aging time required to lock the shuttling dislocations at the wall and may decrease with increase in the loading cycles at the DSA favorable temperature for secondary hardening. At high temperature, with the diffusion of interstitial atoms increasing and the fatigue cycles growth, the aging time $t_{a}$ decreases to lock the mobile dislocations. However, at room temperature, the diffused solute atoms may lock the mobile dislocations at slow dislocation movement at some low strain rate. The aging time $t_{a}$ is inversely proportional to the diffusion coefficient of solute atoms $D_{a}$ and the density of dislocation $\rho_{d}$ at cell walls, such as: $t_{a} \propto \frac{1}{\rho_{d} D_{a}}$, where, $\rho_{d} \propto \rho_{0} N q . \rho_{0}$ is the initial dislocation density.

For the A48 steel, the diffusion of interstitial atoms such as carbon and nitrogen strain rate may get sufficient energy to follow and lock some dislocations with shuttling motion between the dislocation walls at $200{ }^{\circ} \mathrm{C}$ and $0.4 \% \mathrm{~s}^{-1}$. The aging time is estimated as:

$t_{a}=k \frac{L^{2}}{N q D_{a}}$

Where, $q=\frac{1}{2} \Delta \varepsilon_{p \max }$ is the plastic deformation amplitude [16]; $N$ is the number of cycles; $k$ is the proportionality constant and $L$ is the average length of the walls in the secondary cyclic hardening process. At the secondary hardening, when the waiting time satisfies the aging time $\left(t_{w}=t_{a}\right)$ at the appropriate temperature, strain rate conditions and the critical cycle, the onset of the secondary hardening is determined as:

$N_{c}=K \frac{L^{2}}{q D_{a} t_{a}}$

The diffusion coefficient $D_{a}$ is:

$D_{a}=D_{0} \exp \left(-\frac{Q}{R_{g} T}\right)$

$D_{0}$ is temperature independent constant; $Q$ is activation energy of the solute atoms diffusion process; $R_{g}$ is the molar gas constant [20,21]; $T$ is the test temperature.

When the isotropic hardening is considered to a smooth specimen, the uniaxial stress is composed as [16]:

$\sigma=\sigma_{y}+\sum_{i} \alpha^{(i)}+\sum_{k} R^{(k)}$

Where, $\alpha^{(i)}$ is the back stress; $\sigma_{y}$ is the cyclic yield stress; $R^{(k)}$ is the isotropic hardening stress with the sum of 3 parts [22]:

$R=\sum_{k=1}^{3} R^{(k)}$

Each of them shares a unified expression:

$\dot{R}^{(k)}=b_{c}^{(k)}\left(R_{c}^{(k)}-R^{(k)}\right) \dot{p}$

Where, $b_{c}^{(k)}$ is the isotropic hardening/softening rate which is variable in different isotropic hardening period. According to the analysis of the HSH process (Fig. 8), a simple power function with threshold is proposed for the hardening rapidity:

$b_{c}^{(k)}=b_{0}\left\langle p-p_{s}^{(k)}\right\rangle^{n^{(k)}}$

Where, $p_{s}^{(k)}$ is the threshold which is used to control the appearance time for different hardening/softening behavior with accumulated plastic deformation. Parameter $n^{(k)}$ is used to manage the variation of the hardening rapidity with accumulated plastic deformation increasing

In the first cyclic hardening $(k=1)$, the hardening rapidity parameter $b_{c}^{(1)}$ is set equal to $b_{0}$ with $p_{s}^{(1)}=0$ and $n^{(1)}=0$.

In the next cyclic softening period $(k=2)$, the softening rate $b_{c}^{(2)}$ is proposed as:

$b_{c}^{(2)}=b_{0}\left\langle p-p_{c s}\right\rangle^{n^{(2)}}$

The origin of the secondary hardening is variable and can be attributed to the accumulated mobile dislocations in the nucleation sites.

In the third period $(k=3), b_{c}^{(3)}$ is expressed as:

$b_{c}^{(3)}=b_{0}\left\langle p-p_{a s}\right\rangle^{n^{(3)} / 2 q}$

$b_{c}^{(3)}$ is used to describe the DSA hardening speed. As it lasts for a long time, the parameter is closely related to the accumulated plastic deformation with a threshold $p_{a s}$ defined as the accumulated plastic strain at the onset of aging $N_{C}$ :

$p_{a s}=4 \sum_{n=1}^{N_{C}} \frac{\Delta \varepsilon_{p}(n)}{2}$

Owing to the influence of the load amplitude in LCF, $R_{c}^{(k)}$ (Eq.18) is considered as a function of $q$ (the plastic strain amplitude), a memory variable introduced in the references $\underline{[14,15]}$ for the cyclic hardening period before considering the DSA effect.

$R_{c 1}^{(k)}=R_{M}^{(k)}-\left(R_{M}^{(k)}-R_{0}^{(k)}\right) \exp \left(-2 \mu^{(k)} q\right)(k=1, \cdot 2)$

Where, $R_{M}^{(k)}, R_{0}^{(k)}$ and $\mu^{(k)}$ can be considered as constant.

If $k=1$ or 3 , the DSA hardening process in LCF can be calculated by the method [16] with the aging time:

$\dot{t}_{a}=1-\frac{t_{a}}{w(p)} \dot{p}$

The expression for $R_{c}^{(1,3)}$ in the primary and secondary hardening period with DSA effect is:

$R_{c}^{(k)}=R_{c 1}^{(k)}+R_{a s}^{(k)}\left(R, t_{a}\right)(\mathrm{k}=1,3)$ 
where, $R_{c 1}^{(k)}$ is the cyclic hardening part caused by the accumulated plastic deformation given by Eq. (18). $R_{a s}^{(k)}\left(R, t_{a}\right)$ is the DSA hardening part and is expressed as:

$R_{a s}^{(k)}\left(R, t_{a}\right)=P_{1}^{(k)}\left(C_{1}+C_{2} R\right)\left[1-\exp \left(-P_{2} t_{a}^{m}\right)\right]$

The impact of DSA effect on different hardening stage can be introduced by the parameter $P_{1}^{(k)} C_{1}$ and $P_{1}^{(k)} C_{2}$.

When the accumulated plastic deformation reaches the secondary hardening threshold $\left(p_{a s}\right)$, the rule with the DSA effect is:

$\dot{R}^{(3)}=b_{c}^{(3)}\left[R_{c}^{(3)}\left(R, t_{a}\right)-R^{(3)}\right] \dot{p}$

\section{Kinematic hardening with DSA effect}

The kinematic hardening model is a nonlinear law formulated by a series of differential equations. The deformation in the low cycle fatigue can be divided into:

$\varepsilon=\varepsilon^{\mathrm{e}}+\varepsilon^{\mathrm{p}}$

$\dot{\boldsymbol{\varepsilon}}^{\mathbf{p}}=\dot{\lambda} \frac{\partial f}{\partial \boldsymbol{\sigma}}$

The back stress is the superimposed to be independent variables:

$\boldsymbol{\alpha}=\sum_{i} \boldsymbol{\alpha}^{(i)}$

The kinematic hardening is influenced by the isotropic hardening [16] through the parameter $\beta$. In Figs. 6 and 7, it can be observed that the increase of the tangent slope of the hysteresis loops in the plastic deformation period is faster than the yield stress with the increase in the loading cycles. The isotropic hardening due to the DSA affects the kinematic hardening and is presented by the interaction parameter $\beta$. The back stress can be described as:

$\dot{\boldsymbol{\alpha}}^{(i)}=\frac{2}{3} C^{(i)} \dot{\boldsymbol{\varepsilon}}^{p}-\frac{D^{(i)}}{1+\beta R(p)} \boldsymbol{\alpha}^{(i)} \dot{p}$

$R(p)$ is considered to be constant in a cycle where the value of $C^{(i)}$ or $\frac{D^{(i)}}{1+\beta(p, q) R(p)}$ governs the form of the hysteresis loops of LCF. Parameter $\beta$ does not remain constant in the cyclic process. In Fig. 6 and Fig.7, the tangent slope increases rapidly after several hundred loading cycles due to the DSA effect. $\beta$ is assumed to contain a threshold of the aging $\left(p_{a s}\right)$ which is used to improve the capabilities of the A-F multi-kinematic hardening model to reproduce the isotropic hardening with DSA effects. It has a logarithmic proportionality relation with the number of cycles in regard to the coefficient of dynamic recovery term:

$\beta(p, q)=\beta_{0} \frac{\left\langle p-p_{a s}\right\rangle}{\left|p-p_{a s}\right|} \log \left(1+\frac{p}{2 q}\right)$

A successive substitution algorithm is applied according to the work of Hartmann and Haupt [23] with a convergence condition for solving the nonlinear equations. Considering an interval from a state $\mathrm{n}$ to $n+1$ from Eq. (23) to Eq. (27), the backward Euler method allows them to be discretized and the detail information is given in the appendix of the article.

\section{Identification and verification}

The given model includes the nonlinear isotropic and kinematic
Table 2

Parameters of prediction for the second hardening model for $\mathrm{A} 48$ at $200{ }^{\circ} \mathrm{C}$.

\begin{tabular}{llllll}
\hline$Q(\mathrm{~J} / \mathrm{mol})$ & $D_{0}\left(\mathrm{~m}^{2} / \mathrm{s}\right)$ & $R_{g}\left(\mathrm{~J} \mathrm{~K}^{-1} / \mathrm{mol}\right)$ & $L(\mathrm{~m})$ & $T_{0}(k)$ & $K$ \\
\hline 84,100 & $2 \times 10^{-6}$ & 8.31 & $5 \times 10^{-7}$ & 473 & $1.4 \times 10^{-2}$ \\
\hline
\end{tabular}

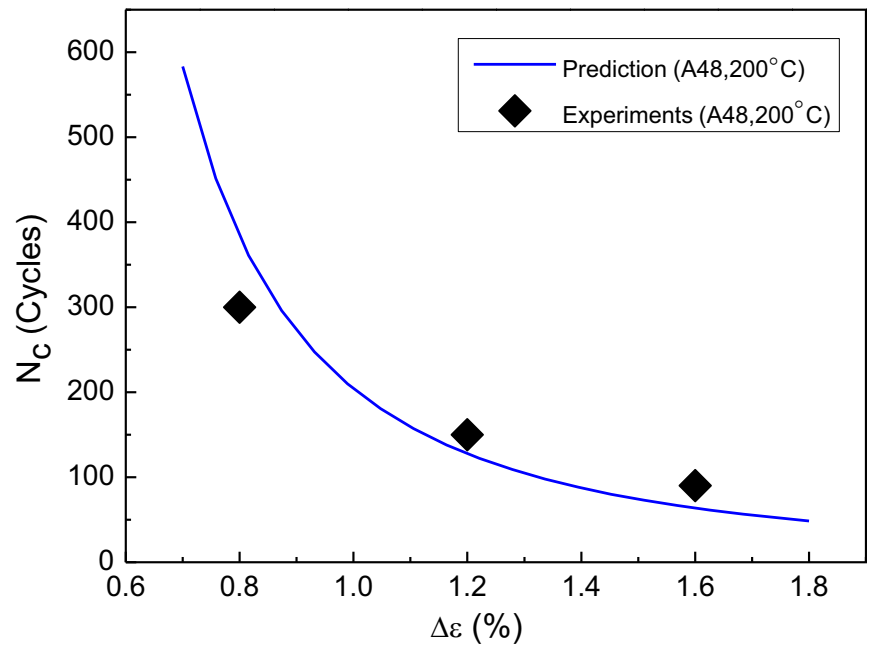

Fig. 9. Secondary hardening prediction and experimental results for $\mathrm{A} 48$ at $200{ }^{\circ} \mathrm{C}$ $0.4 \% \mathrm{~s}^{-1}$.

hardening rules applied to cyclic loads for the A48 steel with DSA effect. The cyclic yield stress can be considered as the sum of the initial yield stress $\sigma_{0}$ and the variation of the elastic domain size $(R)$ in LCF due to the isotropic hardening. According to the test results (Fig.3), when the number of cycles reaches about 20 $\left(p_{c s} \approx 0.3\right)$, the isotropic hardening attains the first peak stress point and starts to decline later.

The onset cycle of secondary hardening $\left(N_{\mathrm{C}}\right)$ is determined as the time of cell shuttling for the dislocations equals to the aging time. The parameters are listed in Table $2[16,17,19]$. The proportional parameter $K$ is determined by the test results. The $N_{\mathrm{C}}$ prediction is shown and compared with the test results at $200{ }^{\circ} \mathrm{C}$ in Fig.9.

Eqs. (13), (15) and (18) are used to describe the cyclic hardening and cyclic softening for A48. The parameters are determined according to the peak tensile stress evolution from the test results as shown in Table 3. The stress $R_{\mathrm{c}}^{(1,3)}$ in Eq. (20) used to reflect the DSA effect on the isotropic hardening, can be determined by various strain rate test. The DSA aging time in Eq. (19) is closely related with the plastic strain rate $\dot{p}$ and the accumulated plastic strain $p$. As shown in reference [16], the exponent parameter $m$ defines the size of the negative strain rate sensitivity domain while $P_{2}$ and $w$ show similar effect to delay DSA in Eq. (21). The evolution of the aging stress $\left(R_{\mathrm{as}}\right.$ for $0.8 \%, 0.6 \%, 0.4 \%$ strain amplitude) against the plastic strain rate for the primary and secondary DSA hardening is shown in Fig. 10 and Fig. 11 (the parameters are listed in Table 4).

Simulation parameters for A48 kinematic hardening are determined by the uniaxial LCF tests of A48 steel at RT and $200{ }^{\circ} \mathrm{C}$. The stress-strain hysteresis loop in the beginning of the tests was

Table 3

Parameters for prediction the first hardening and softening model for A48 at $200{ }^{\circ} \mathrm{C}$.

\begin{tabular}{lllllllllll}
\hline $\mathrm{b}_{\mathrm{ch}}$ & $\mathrm{n}^{(1)}$ & $\mathrm{n}^{(2)}$ & $\mathrm{p}_{\mathrm{cs}}$ & $R_{M}^{(1)}(\mathrm{MPa})$ & $R_{0}^{(1)}(\mathrm{MPa})$ & $\mu^{(1)}$ & $R_{M}^{(2)}(\mathrm{MPa})$ & $R_{0}^{(2)}(\mathrm{MPa})$ & $\mu^{(2)}$ \\
\hline 13 & 0 & 1.2 & 0.3 & 135 & 10 & 80 & 55 & 2 & 20 \\
\hline
\end{tabular}




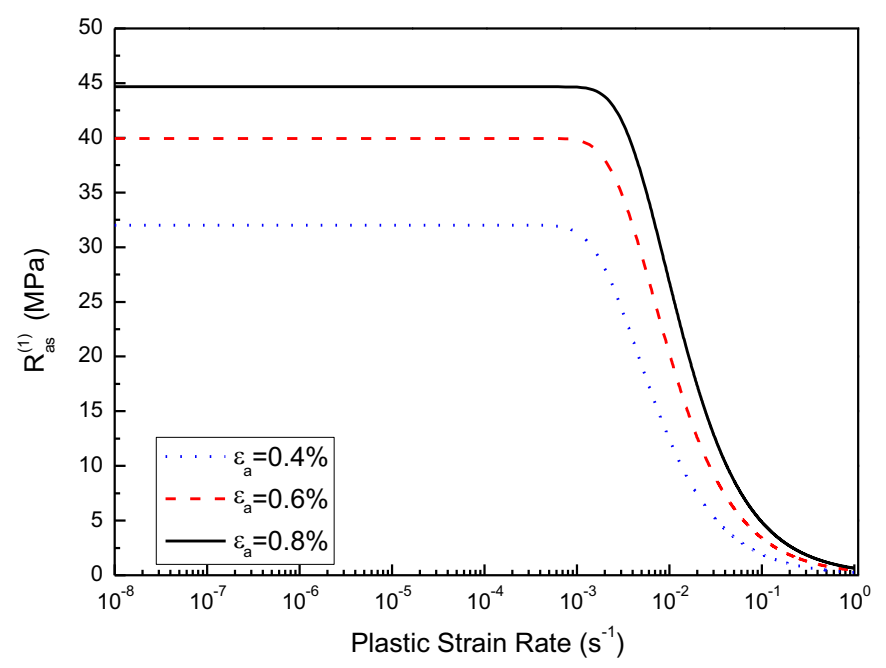

Fig. 10. Evolution of the aging stress in primary hardening period with plastic strain rate.

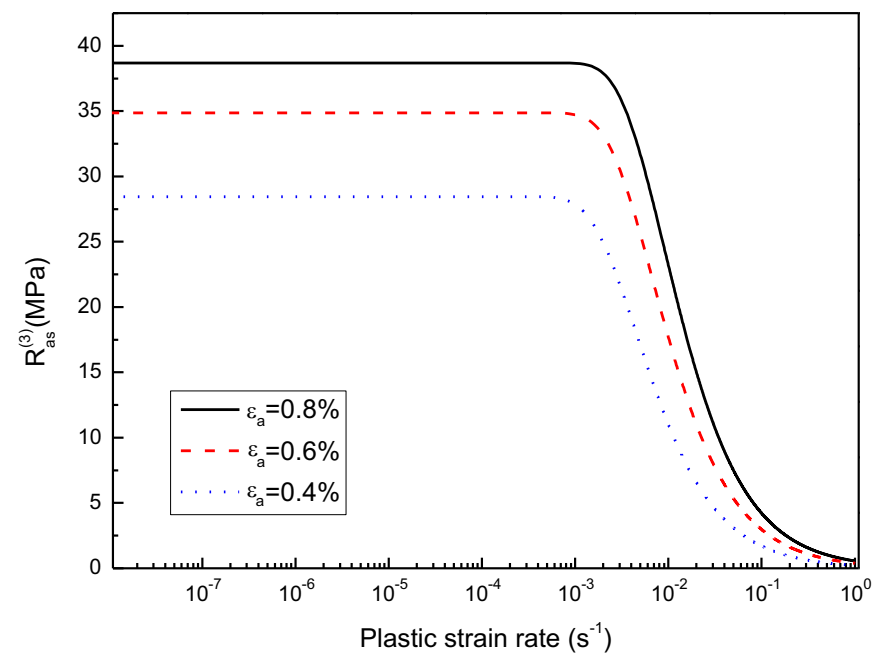

Fig. 11. Evolution of the aging stress in the secondary hardening period with plastic strain rate.

Table 4

DSA hardening parameters for A48 at $200{ }^{\circ} \mathrm{C}$.

\begin{tabular}{lllllll}
\hline $\mathrm{C}_{1}$ & $\mathrm{C}_{2}$ & $\mathrm{~m}$ & $\mathrm{P}_{1}^{(1)}$ & $\mathrm{P}_{2}$ & $\mathrm{P}_{1}^{(2)}$ & $\mathrm{n}^{(3)}$ \\
\hline 8 & 0.8 & 0.9 & 0.45 & 0.6 & 0.7 & 0.0028 \\
\hline
\end{tabular}

used. Only cyclic hardening was considered to obtain the material parameters as mentioned in the report [11].

The hysteresis loops for A48 at $0.032 \% \mathrm{~s}^{-1}$ and $3.2 \% \mathrm{~s}^{-1}$ (RT) are simulated in Figs. 12 and 13. It can be seen in Figs. 14-16 that the prediction of the modified A-F model with DSA effect for 0.8 , 0.6 and $0.4 \%$ strain amplitude and different isotropic hardening stages showed fair agreement with the experimental values. The peak stress evolutions in the LCF tests for the strain amplitude were well estimated at RT and $200{ }^{\circ} \mathrm{C}$ as shown in Figs. 17 and 18 (Table 5).

\section{Conclusions}

This study investigates the LCF cyclic behavior of A48 steel in the steam generator pipes of nuclear plant with the DSA effect at

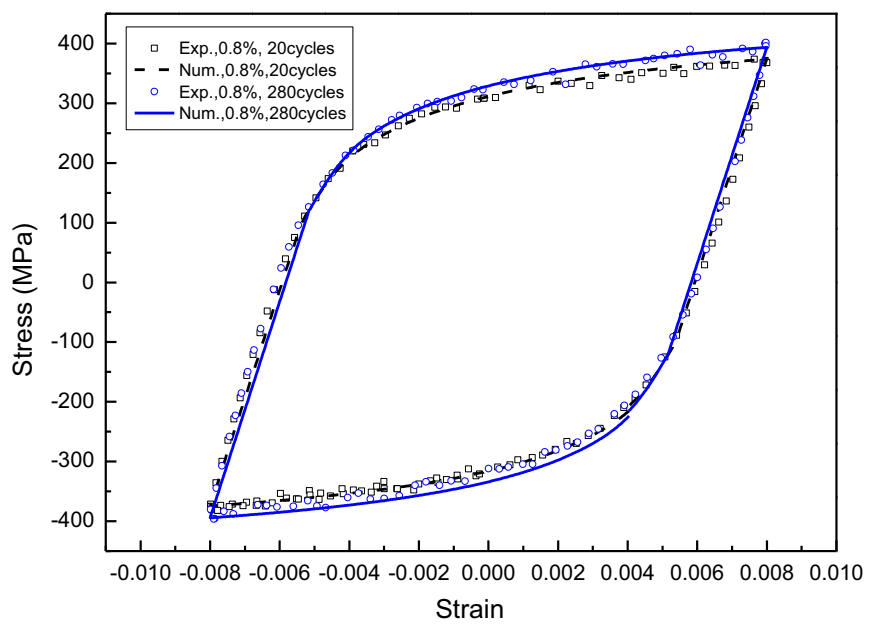

Fig. 12. A48, $0.8 \%, 0.032 \% \mathrm{~s}^{-1}$, RT, stress versus strain.

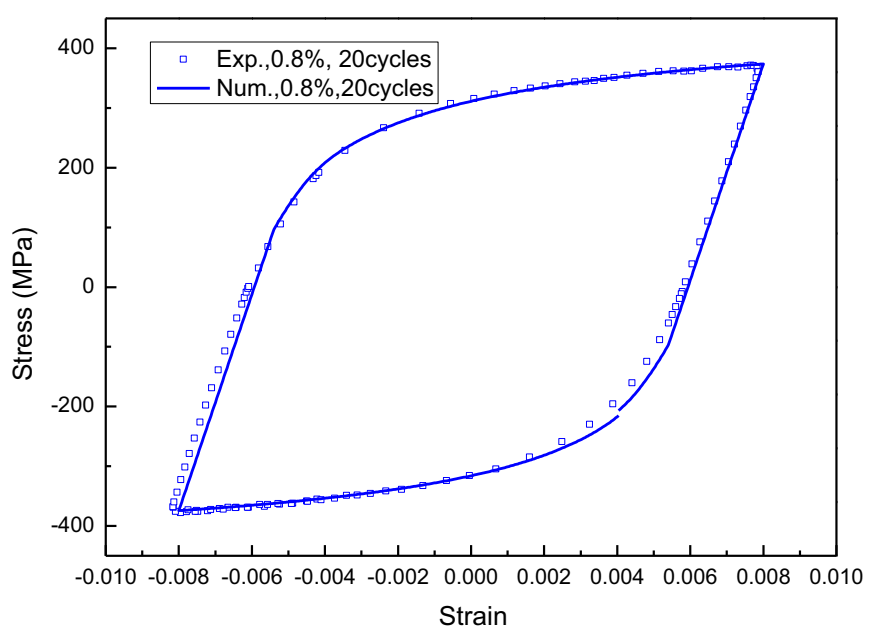

Fig. 13. $A 48,0.8 \%, 3.2 \% \mathrm{~s}^{-1}$, RT, stress versus strain.

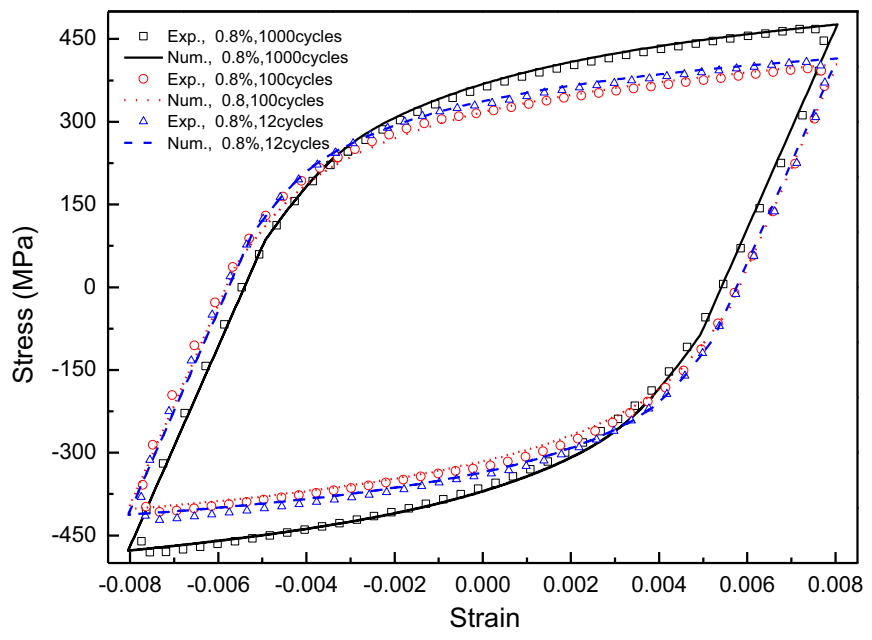

Fig. 14. $\mathrm{A} 48,0.8 \%, 0.4 \% \mathrm{~s}^{-} 1200{ }^{\circ} \mathrm{C}$, stress versus strain.

$200^{\circ} \mathrm{C}$. The $\mathrm{HCH}$ cyclic stress evolution in the LCF is caused by the effects of cumulative plastic deformation and DSA at $200{ }^{\circ} \mathrm{C}$ and $0.4 \% \mathrm{~s}^{-1}$ strain rate. Based on the framework of thermodynamic, the kinematic and isotropic rules have been modified with considering the DSA effect. The DSA stress dependency on the strain rate was also evaluated to describe the secondary hardening of the peak tensile stress in LCF. The plastic deformation and cyclic stress 


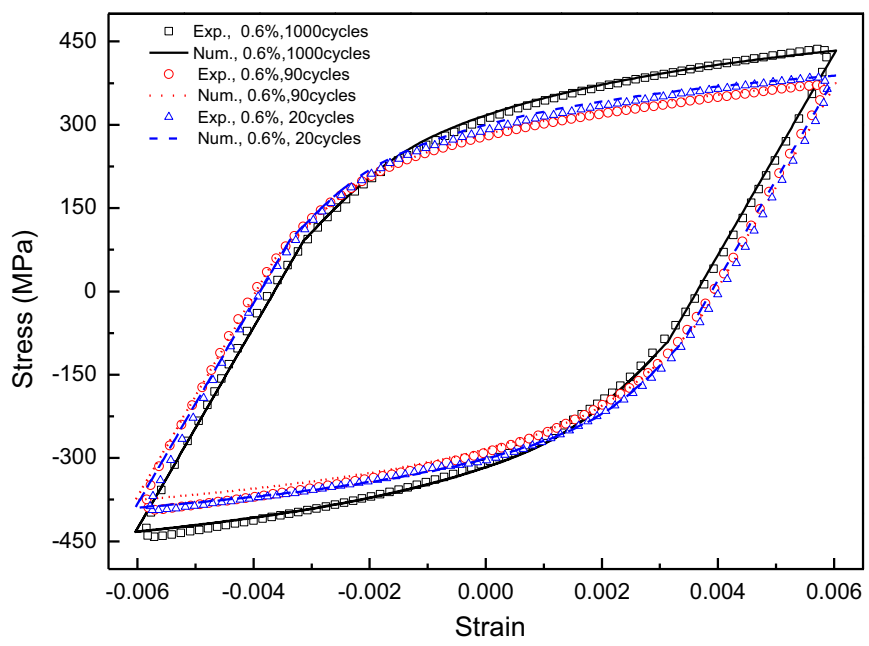

Fig. 15. $\mathrm{A} 48,0.6 \%, 0.4 \% \mathrm{~s}^{-} 1200{ }^{\circ} \mathrm{C}$, stress versus strain.

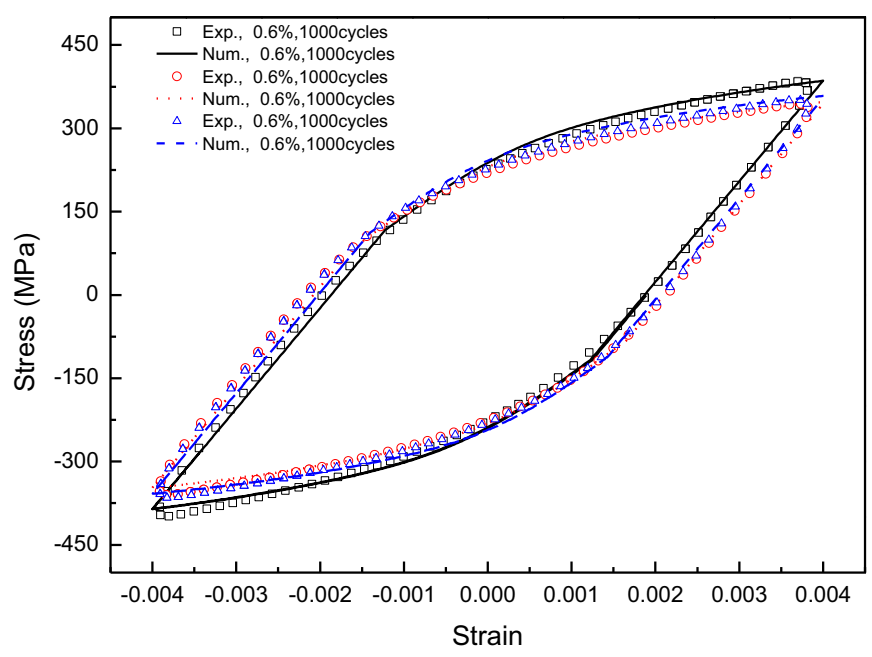

Fig. 16. $\mathrm{A} 48,0.4 \%, 0.4 \% \mathrm{~s}^{-} 1,200{ }^{\circ} \mathrm{C}$, stress versus strain.

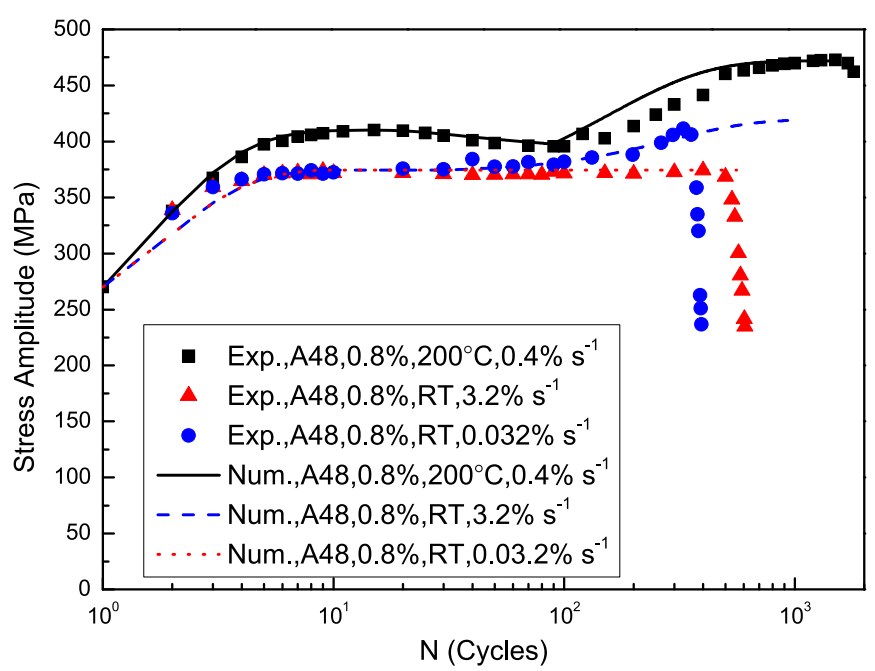

Fig. 17. Evaluation of stress amplitude versus cycle in LCF for A48 at room temperature (RT) and $200{ }^{\circ} \mathrm{C}$ with stain rates.

were calculated by the modified model with the help of the return back implicit integration method and showed agreement with the experimental data.

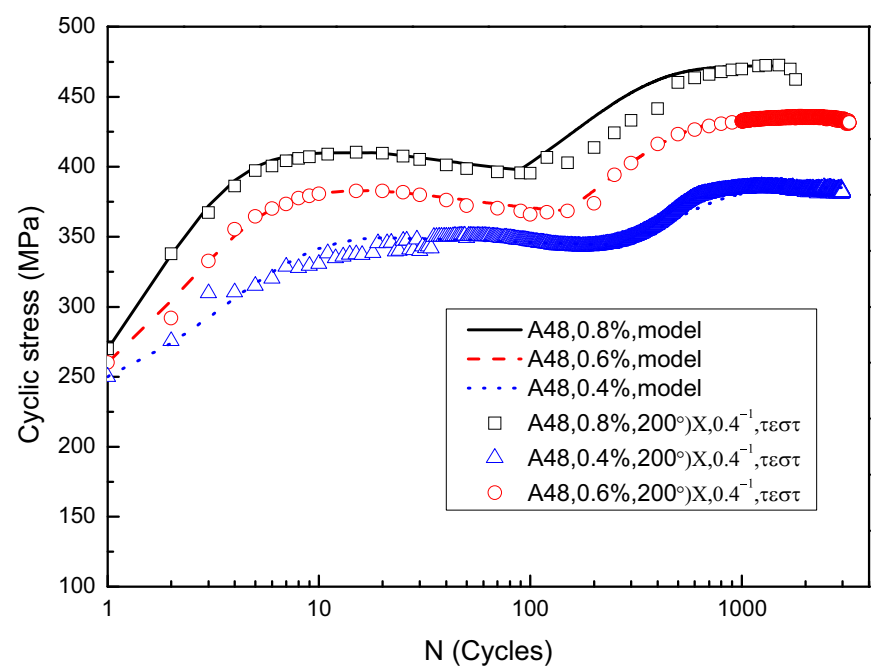

Fig. 18. Evaluation of stress amplitude versus cycle in LCF for A48 $200^{\circ} \mathrm{C}$.

Table 5

Kinematic hardening parameters of A48 at room temperature.

\begin{tabular}{llllllll}
\hline$\zeta_{1}$ & $\zeta_{2}$ & $\zeta_{3}$ & $\zeta_{4}$ & $\zeta_{5}$ & $r_{1}(\mathrm{MPa})$ & $r_{2}(\mathrm{MPa})$ & $r_{3}(\mathrm{MPa})$ \\
\hline 4500 & 850 & 321 & 217 & 163 & 57 & 46 & 35 \\
$r_{4}(\mathrm{MPa})$ & $r_{5}(\mathrm{MPa})$ & $\beta_{0}$ & & & & & \\
20 & 7 & 0.0015 & & & & & \\
\hline
\end{tabular}

\section{Acknowledgments}

Financial support by National Natural Science Foundation of China, China (No. 11372201) and AREVA, France is gratefully acknowledged.

\section{Appendix A. Discretization and integration}

All constitutive variables in Eqs. (23-27) at step n combining with $\Delta \varepsilon_{n+1}$ are used to find $\sigma_{n+1}$ in order to satisfy the discretized constitutive relations in Eqs. (A-1)-(A-13).

$\varepsilon_{n+1}=\varepsilon_{n+1}^{e}+\varepsilon_{n+1}^{p}$

$\varepsilon_{n+1}^{p}=\varepsilon_{n}^{p}+\Delta \varepsilon_{n+1}^{p}$

$\boldsymbol{\sigma}_{n+1}=\mathbf{D}^{\mathbf{e}}:\left(\boldsymbol{\varepsilon}_{n+1}-\boldsymbol{\varepsilon}_{n+1}^{p}\right)$

$\Delta \varepsilon_{n+1}^{p}=\sqrt{\frac{3}{2}} \Delta p_{n+1} \mathbf{n}_{n+1}$

$\mathbf{n}_{n+1}=\sqrt{\frac{3}{2}} \frac{\mathbf{s}_{n+1}-\boldsymbol{\alpha}_{n+1}}{Y_{n+1}}$

$F_{n+1}=\frac{3}{2}\left(\mathbf{s}_{n+1}-\boldsymbol{\alpha}_{n+1}\right):\left(\mathbf{s}_{n+1}-\boldsymbol{\alpha}_{n+1}\right)-Y_{n+1}^{2}$ 
$\boldsymbol{\alpha}_{n+1}=\sum_{i=1}^{M} \boldsymbol{\alpha}_{n+1}^{(i)}$

$\boldsymbol{\alpha}_{n+1}^{(i)}=\boldsymbol{\alpha}_{n}^{(i)}+\left(\frac{2}{3} C^{(i)} \Delta \varepsilon_{n+1}^{p}-\frac{D^{(i)}}{1+\beta R_{n+1}\left(p_{n+1}\right)} \boldsymbol{\alpha}_{n+1}^{(i)} \Delta p_{n+1}^{(i)}\right)$

$\Delta R_{n+1}^{(k)}=b^{(k)}\left(R_{c}^{(k)}-R_{n}^{(k)}\right) \Delta p_{n+1}$

$\Delta R_{n+1}=\sum_{k=1}^{3} \Delta R_{n+1}^{(k)}$

$Y_{n+1}=\left(Y_{n}+\Delta R_{n+1}\right)$

Where,

$\beta=\beta_{0} ; \quad$ if $p_{n+1} \leq p_{0}$

$\beta=\beta_{0} \log N ; \quad$ if $p_{n+1}>p_{0}$

The return mapping method is applied here, including an elastic predictor and a plastic corrector $[24,25]$. An elastic tentative stress $\boldsymbol{\sigma}_{n+1}^{*}$ is given to predict the next stress step before plastic correction:

$\boldsymbol{\sigma}_{n+1}^{*}=\mathbf{D}^{\mathbf{e}}:\left(\varepsilon_{n+1}-\varepsilon_{n}^{p}\right)$

The yield condition is:

$F_{n+1}^{*}=\frac{3}{2}\left(\mathbf{s}_{n+1}^{*}-\boldsymbol{\alpha}_{n}\right):\left(\mathbf{s}_{n+1}^{*}-\boldsymbol{\alpha}_{n}\right)-Y_{n}^{2}$

Where, $\mathbf{s}_{n+1}^{*}$ is the deviatoric part of $\boldsymbol{\sigma}_{n+1}^{*}$. If $F_{n+1}^{*} \geq 0, \boldsymbol{\sigma}_{n+1}$ is on the yield surface and the stress is:

$\boldsymbol{\sigma}_{n+1}=\boldsymbol{\sigma}_{n+1}^{*}-\mathbf{D}^{\mathbf{e}}: \Delta \varepsilon_{n+1}^{p}$

The term $\mathbf{D}^{\mathbf{e}}: \Delta \varepsilon_{n+1}^{p}$ is the plastic corrector and can be rewritten as $2 G \Delta \varepsilon_{n+1}^{p}$ with the elastic isotropy and plastic incompressibility assumption. The stress in Eq. (24) is substituted by the deviatoric part of $\sigma_{n+1}$ :

$\mathbf{s}_{n+1}-\boldsymbol{\alpha}_{n+1}=\mathbf{s}_{n+1}^{*}-2 G \Delta \varepsilon_{n+1}^{p}-\sum_{i=1}^{M} \boldsymbol{\alpha}_{n+1}^{(i)}$

$G=\frac{E}{2(1+v)}$

$G$ represents the plastic shear modulus. The plastic poisson's ratio $v$ is assigned 0.5 in the above equation when plastic flow occurs. $\boldsymbol{\alpha}_{n+1}^{(i)}$ is obtained from equation (A-8) as:

$\boldsymbol{\alpha}_{n+1}^{(i)}=\theta_{n+1}^{(i)}\left(\boldsymbol{\alpha}_{n}^{(i)}+\frac{2}{3} C^{(i)} \Delta \varepsilon_{n+1}^{p}\right)$

where $\theta_{n+1}^{(i)}$ is defined by the following equation and satisfies $0<\theta_{n+1}^{(i)} \leq 1$

$\theta_{n+1}^{(i)}=\frac{1+\beta R_{n+1}\left(p_{n+1}^{(i)}\right)}{1+\beta R_{n+1}\left(p_{n+1}^{(i)}\right)+D^{(i)} \Delta p_{n+1}^{(i)}}$

Using Eqs. (A-3), (A-4) to eliminate $\Delta \varepsilon_{n+1}^{p}$ in Eqs. (A-16), (A-17), we can obtain:

$\mathbf{s}_{n+1}-\boldsymbol{\alpha}_{n+1}=\frac{Y_{n+1}\left(\mathbf{s}_{n+1}^{*}-\sum_{i=1}^{M} \theta_{n+1}^{(i)} \boldsymbol{\alpha}_{n}^{(i)}\right)}{Y_{n+1}+\left[3 G+\sum_{i=1}^{M} \theta_{n+1}^{(i)} C^{(i)}\right] \Delta p_{n+1}}$
Eq. (A-21) is then applied to the yield condition $F_{n+1}=0$, and a non-linear scalar equation $\Delta p_{n+1}$ can be found:

$\Delta p_{n+1}=\frac{\left[3 / 2\left(\mathbf{s}_{n+1}^{*}-\sum_{i=1}^{M} \theta_{n+1}^{(i)} \boldsymbol{\alpha}_{n}^{(i)}\right):\left(\mathbf{s}_{n+1}^{*}-\sum_{i=1}^{M} \theta_{n+1}^{(i)} \boldsymbol{\alpha}_{n}^{(i)}\right)\right]^{1 / 2}-Y_{n+1}}{3 G+\sum_{i=1}^{M} \theta_{n+1}^{(i)} C^{(i)}}$

where, $\theta_{n+1}^{(i)}$ and $Y_{n+1}$ are function of $\Delta p_{n+1}^{(i)}$ and $\Delta p_{n+1}$, respectively.

All internal variables corresponding to the end of increment $\mathrm{n}+1$ can use the above nonlinear algebraic equations in calculations.

\section{References}

[1] Zhi Yong HUANG, D. WAGNER, C. BATHIAS, J.L. CHABOCHE, Cumulative fatigue damage in low cycle fatigue and gigacycle fatigue for low Carbon Manganese steel, Int. J. Fatigue 33 (2011) 115-121.

[2] J.A. Le Duff, Y. Lehéricy, A. Lefrançois, J. Mendez, Effects of surface finish and LCF pre-damage on the HCF endurance limits of A 304L austenitic stainless steel, Dtsch. Verband fur Mater. und Pruf. e.V (2009) 1023-1033.

[3] R. BORRELY, D. BENKIRAT, Sensibilité du pouvoir thermoélectrique à l'état microstructural du fer du fer-azote, Acta Met. 33 (5) (1985), pp855-pp866.

[4] L.Cheng, N.M van der pers, A. Bottoger, TH. HDE Keijser, E.J. Mittemeijer. Lattice changes of Iron-Carbon Martensites on Aging at Room Temperature, Met. Trans A,Vol. 22A,Sept.91,pp. 1957-1967.

[5] A.H. Cottrell, B.A. Bilby, Dislocation theory of yielding and strain aging of iron, Proc. Phys. Soc. (1949) 49-62 62/I-A.

[6] H. Abdel-Raouf, A. Plumtree, T.H. Topper, Effects of temperature and deformation rate on cyclic strength and fracture of low carbon steel, ASTM-STP 519 (1973) 28.

[7] P.J. Armstrong C.O. Frederick. A Math. Represent. multiaxial bauscinger Eff. CEGB Rep. No. RD/B/N 7311966.

[8] J. Lemaître, J.L. Chaboche, Mechanics of Solid Materials, Cambridge University Press, Cambridge, 1990.

[9] G. Cailletaud, K. Sa16, Study of plastic/viscoplastic models with various inelastic mechanisms, Int. J. Plast. 11 (1995) 991-1005.

[10] D.L. McDowell, Stress state dependence of cyclic ratcheting behavior of two rail steels, Int. J. Plast. 11 (1995) 397-421.

[11] N. Ohno, M. Tsuda, T. Kamei, Elastoplastic implicit integration algorithm applicable to both plane stress and three-dimensional stress states, Finite. Elem. Anal. Des. 66 (2013) 1-11.

[12] G.Z. Kang, Q.H. Kan, J. Zhang, Y. Sun, Time-dependent ratchetting experiments of SS304 stainless steel, Int. J. Plast. 22 (2006) 858-894.

[13] A.S. Khan, S. Huang, Continuum theory of plasticity. A Wiley-Interscience publication, John Wiley \& Sons, New York, 1995.

[14] J.L. Chaboche, A review of some plasticity and viscoplasticity constitutive theories, Int. J. Plast. 24 (10) (2008) 247-302.

[15] D.L. McDowell, Evaluation of intersection conditions for two-surface plasticity theory, Int. J. Plast. 5 (1989) 25-50.

[16] J.-L. Chaboche, A. Gaubert, P. Kanouté, A. Longuet, F. Azzouz, M. Mazière, Viscoplastic constitutive equations of combustion chamber materials including cyclic hardening and dynamic strain aging, Int. J. Plast. 46 (2013) 1-22 ISSN 0749-6419.

[17] D. WAGNER, N. ROUBIER, C. PRIOUL, -Measurement of sensitivity to dynamic strain aging in C-Mn steels by internal friction method, Mat. Sci. Technol. 22-3 (2006) 301-307.

[18] Haël Mughrabi, On the dislocation mechanisms of dynamic strain ageing in fatigued plain carbon steels, Z. für Met. 94 (No. 5) (2003) 471-477.

[19] Byung Ho Lee, In Sup Kim, Dynamic strain aging in the high temperature low cycle fatigue of SA508 Cl. 3 forging steel, J. Nucl. Mater. 226 (1995) 216-225.

[20] P.G. McCormick, Theory of flow localization due to dynamic strain ageing, Acta Met. 36 (12) (1988) 3061-3067.

[21] S. Zhang, P.G. McCormick, Y. Estrin, The morphology of Portevin-Le Chatelier bands: finite element simulation for Al-Mg-Si, Acta Mater. 49 (2001) 1087-1094.

[22] Zhi Yong Huang, Daniele Wagner, Qing Yuan Wang, Bathias Claude, Effect of dynamic strain aging on isotropic hardening in low cycle fatigue for carbon manganese steel, Mater. Sci. Eng.: A 589 (1) (2014) 34-40.

[23] S. Hartmann, P. Haupt, Stress computation and consistent tangent operator using non-linear kinematic hardening models, Int. J. Numer. Methods Eng. 36 (1993) 3801-3814.

[24] J.C. Simo, R.L. Taylor, Consistent tangent operators for rate-independent elsatoplasticity, Meth. Appl. Mech. Eng. 48 (1985) 101-118.

[25] Kobayashi Mineo, Ohno Nobutada, Implementation of cyclic plasticity models based on a general form of kinematic hardeningInt, J. Numer. Meth. Eng. 53 (2002) 2217-2238. 